\title{
FutureJournal
}

\section{Turnover no Varejo: Estudo em uma Rede Supermercadista em Belo Horizonte - MG}

\section{Leandro Souza de Pinho}

Mestrado Profissional em Administração das Faculdades Integradas de Pedro Leopoldo, FPL, Brasil

leandro.pinho@outlook.com

\section{Ester Eliane Jeunon}

Professora Titular na Faculdade Pedro Leopoldo, FPL, Brasil

esterjeunon@gmail.com

\section{Leonora da Cunha Duarte}

Especialização em andamento em Gestão no Agronegócio na Faculdades Associadas de Uberaba, FAZU, Brasil

leonoracduarte@gmail.com

\section{RESUMO}

Este relato apresenta resultados de um estudo de caso sobre a configuração do turnover e seu gerenciamento na Organização Verdemar, empreendimento atuante no varejo alimentício em Belo Horizonte (MG). O objetivo foi identificar os motivos de desligamento na organização e as políticas para seu gerenciamento. Para tanto, realizou-se pesquisa descritiva, com abordagem quantitativa e qualitativa, tendo como método a pesquisa documental (dados do turnover da organização) e de campo (entrevistas a especialistas de $\mathrm{RH}$ e líderes da organização, bem como questionários aplicados a amostra de 253 funcionários). O trabalho nos finais de semanas, 0 expediente característico da atividade e os excessos de faltas e atestados foram os motivos mais representativos para 0 desligamento. As principais práticas de gerenciamento do turnover levantadas foram a melhoria dos critérios de seleção e o treinamento dos profissionais. Verificou-se que organização possui percentuais de turnover abaixo da média nacional do segmento, justificado pela avaliação positiva dos funcionários a respeito das políticas de $\mathrm{RH}$ instituídas. Conclui-se que o investimento nas políticas e práticas de recursos humanos gera resultados tangíveis para o negócio. 
PALAVRAS-CHAVE: Varejo. Turnover. Recursos Humanos.

\section{Turnover in Retailing: Study on a Supermarket Network in Belo Horizonte - MG}

\section{ABSTRACT}

This report presents results of a case study on the configuration of turnover and its management in Verdemar Organization, foodretailing enterprise from Belo Horizonte (MG). The goal was to identify the reasons for job quitting and layoffs in the organization and the phenomenon management policies. Therefore, a descriptive research was carried out in a quantitative and qualitative approach, through documentary research (on the organization data) and field research (interviews with HR specialists and leaders of the organization, as well as a questionnaire applied to a 253-employee sample). Mandatory work on weekends, the activity working hours and excessive absences and medical issues were the most representative reasons for job quitting and layoffs. The main turnover management practices raised were related to the improvement of selection criteria and the training of the employees. It was observed that the organization has turnover percentage below the national average on the segment, justified by the positive evaluation of the employees regarding the HR policies established. It is concluded that investment in human resource policies and practices generates tangible results for the business.

KEY-WORDS: Retail. Turnover. Human Resources. 


\section{Introdução}

Um dos maiores setores da economia mundial, o varejo, responsável pela disponibilização de produtos para o consumidor, tem se transformado rumo à profissionalização. Ao apresentarem uma grande variedade de produtos em horários e quantidade convenientes, os varejistas proporcionam benefícios e criam valor para seus consumidores. O comércio varejista, apesar de apresentar números expressivos na empregabilidade nacional, tem o alto índice de turnover como uma realidade. De acordo com os dados do Departamento Intersindical de Estatística e Estudos Socioeconômicos [DIEESE] (2015), o turnover no comércio varejista é elevado e cresceu nos últimos anos, passando de 55,2\%, em 2007, para 64,2\%, em 2013.

Elevadas taxas de turnover trazem vários impactos negativos, complicando a gestão das empresas e onerando os seus custos. O termo inglês turnover, que em português significa rotatividade, é um indicador relacionado às admissões e demissões de funcionários da organização em determinado período de tempo, comparado à média de funcionários efetivos (Marras, 2000), sendo que essa rotatividade de pessoal pode ser ocasionada por fatores internos e externos à organização (Silva, 2002). Para tratar o turnover, as empresas buscam pesquisar e entender o que o impulsiona, seus impactos mensuráveis, além de definir políticas que irão controlar a movimentação de pessoas no contexto empresarial.

O segmento que mais se destaca no setor varejista é o de supermercados, que vem passando por intensas reestruturações e fusões nos últimos anos. Neste contexto, este relato apresenta os resultados mais relevantes de um trabalho de dissertação sobre a configuração do turnover e seu gerenciamento na Organização Verdemar, empreendimento atuante no varejo alimentício, composto por supermercados e padarias em Belo Horizonte (MG), sendo focado nos anseios e demandas da classe econômica detentora de um maior poder aquisitivo. O negócio é reconhecido pela qualidade dos produtos, serviços e atendimento personalizado, além de se destacar no cenário supermercadista mineiro.

Com o foco de identificar os motivos de desligamento na organização pesquisada nos últimos três anos e as políticas adotadas para o seu gerenciamento, este relato constitui-se em: o referencial que permite o 
enquadramento do problema do ponto de vista teórico, a metodologia que descreve os tipos de pesquisas e abordagens adotadas, seguida da apresentação dos resultados obtidos e de sua análise e, finalmente, das conclusões mais relevantes apresentadas na pesquisa original.

Sendo o turnover um problema para as organizações e a elevada taxa desse indicador no segmento do varejo uma realidade percebida, esta pesquisa justifica-se, em termos teóricos, por buscar ampliar o conhecimento em torno do tema e sobre seu melhor gerenciamento. Os resultados obtidos no estudo revelaram a preocupação dos investigados com os custos financeiros e a queda do desempenho, assim como foram evidenciados aspectos negativos do segmento varejista, sendo os mais citados: o trabalho nos finais de semana, baixos salários e pouco investimento na formação dos profissionais.

Acredita-se, portanto, que a pesquisa relatada poderá contribuir para o conhecimento científico em administração e auxiliar na melhoria das políticas e práticas organizacionais que poderão atender às demandas das empresas e de seus funcionários, proporcionando melhorias para ambas as partes.

\section{Referencial Teórico}

As relações humanas no trabalho se formam em uma sequência gradual de integração entre os indivíduos em uma dada situação de trabalho, proporcionando a colaboração dos trabalhadores para com a empresa e, simultaneamente, encontrando a satisfação de suas necessidades sociais e psicológicas nelas. Para Ulrich (1998), em termos estratégicos, a gestão de recursos humanos tem como objetivo maior buscar um grau mais elevado de coerência possível entre as políticas organizacionais e os fatores ambientais presentes no meio social. Para isso, é fundamental que os profissionais de RH sejam parceiros dos negócios e gestores de mudanças. Dessa forma, o desafio do RH tornou-se maior, já que a empresa depende do maior envolvimento dos funcionários para garantir resultados e se garantir na competição de mercado. Ou seja, as políticas e práticas de RH ficaram mais complexas e necessárias para atingir os objetivos organizacionais e de RH. 
Neste sentido, o arcabouço teórico da pesquisa tem como foco o fenômeno do turnover, apresentando sua conceituação, importância, aspectos motivadores e mediadores, assim como suas consequências, incluindo a relevante questão da retenção de empregados como forma de mitigar os impactos dos desligamentos, tais como os custos inerentes ao processo e a perda de talentos.

\subsection{Turnover}

De acordo com Marras (2000, p. 66), turnover "é o número de empregados desligados da empresa num determinado período comparativamente ao quadro médio de efetivos. A rotatividade é expressa por um número índice, que recebe o nome de índice de rotatividade". Os índices de turnover são calculados mensalmente e a soma dos resultados configura o índice anual. Esse índice demonstra, em valor percentual, a quantidade de pessoas que circulam na organização.

Cabe ao administrador pesquisar os motivos do turnover em sua empresa; entender quando é natural e necessária a movimentação de pessoas, saber das consequências e seus impactos nos negócios e definir ações para tratar o fenômeno. Além disso, o trabalho preventivo irá controlar esse indicador. O administrador deve prever e se preparar para mudanças no mercado (Mobley, 1992). O estilo de liderança e o clima no ambiente de trabalho também impactam na rotatividade de pessoal. Criar um ambiente agradável no trabalho ajuda os funcionários a desempenharem melhor suas funções. O autor destaca aspectos positivos do turnover ao afirmar que índices pouco representativos e estáveis podem representar uma saudável rotatividade, pois é importante renovar o quadro de funcionários. A constante entrada de profissionais que irão substituir os absenteístas, desinteressados ou não produtivos oxigena as equipes com novas ideias e novos conhecimentos. Então, o objetivo da empresa pode ser controlar o indicador de rotatividade de pessoas e não torná-lo nulo. Todavia, tal abordagem não exclui a necessidade de se estudar o fenômeno, posto que índices elevados ou zerados não são interessantes, pelos custos e estagnação da mão de obra, respectivamente. E o ponto crítico do elevado turnover é quando este é caracterizado pela perda de profissionais talentosos, diferenciados e que 
serão absorvidos pelos concorrentes, levando conhecimento específico do negócio e, em alguns casos, clientes.

Em relação aos aspectos motivadores do turnover, Morrell, Loan-Clarke e Wilkinson (2001) dizem que as movimentações do mercado, a oferta de trabalho em determinado setor, o índice de desemprego, os tipos de funções, as propostas salariais, o estresse ocasionado pela natureza da atividade e o clima no ambiente de trabalho acompanhado da motivação são fatores que antecedem a intenção de permanecer ou não em um emprego.

A intenção de abandonar um emprego não surge de um fator isolado. As relações com os colegas de trabalho e líderes, questões pessoais, questões familiares, interesse pela atividade desenvolvida devem ser levados em conta quando se fala de estímulo para romper um vínculo trabalhista. Dessa forma, conhecer a opinião dos empregados ajuda a prever comportamentos futuros. Consequentemente, a empresa poderá criar ações para nortear esse comportamento de forma a conduzir para uma retenção. Mobley (1992) menciona um modelo "expandido" destinado ao entendimento dessa relação ao unir elementos de outros modelos e tratar as variáveis da organização, do ambiente e do indivíduo associadas ao turnover. Nesse modelo, há quatro determinantes básicos das intenções de sair e do subsequente turnover: a) satisfação-insatisfação no cargo; b) expectativa da utilidade de papéis profissionais alternativos e internos (à organização); c) expectativa da utilidade de papéis profissionais externos (à organização); e d) valores e contingências não ligados ao trabalho.

Outro aspecto importante sobre o tema refere-se aos mediadores do turnover, isto é, aqueles intermediários à sua concretização. Neste contexto, a gestão de recursos humanos é o setor responsável pela mediação dos interesses entre o empresário e o trabalhador. Por isso, o turnover é um indicador de corresponsabilidade do setor. E a eficácia na gestão desse indicador é um dos maiores desafios para a GRH, já que existe uma diferença entre querer sair da empresa e efetivamente se desligar, pois um funcionário pode ter a intenção de sair, mas não concretizar o turnover (Mobley, 1992).

Conforme citado por Lacombe e Albuquerque (2008), índices elevados de turnover são sintomas de que a gestão de recursos humanos na organização pode estar adotando práticas equivocadas. Se esse alto índice não for resultado de alguma estratégia necessária às mudanças ou não 
trouxer algum tipo de ganho, o indicador precisa ser tratado com prioridade. As empresas vão entendendo a necessidade de reter profissionais no cenário globalizado, mas, principalmente, começam a entender que a rotatividade é um forte indício de que existem distorções na política de recursos humanos.

No que se refere às consequências do turnover, Mobley (1992) destaca que a perda de um funcionário implica perda de investimento. Mas também há perda do conhecimento específico do negócio, levado pelo funcionário que deixa a organização. Identificar as reais causas que levam o profissional a deixar uma organização possibilita resolver o problema antecipadamente e, se for o caso, procurar soluções alternativas (Menicucci \& Jeunon, 2008).

Para Dutra (2011), os custos relacionados à rotatividade estão definidos como: custos primários (ocasionados imediatamente para a substituição do funcionário); custos secundários (podem ser quantitativos e de efeitos intangíveis); e custos terciários (difíceis de serem mensurados e são sentidos a médio e longo prazo). Fala-se do custo financeiro, mas outra decorrência preocupante do turnover é fortificar o concorrente ou até mesmo criar novas concorrências. O colaborador qualificado pode ingressar na concorrência direta, compartilhando toda expertise adquirida na empresa anterior; ou firmar seu próprio negócio, tornando-se concorrente no segmento.

Entre as consequências que o turnover pode trazer, é importante lembrar as implicações positivas para as organizações. Rescindir com funcionários de desempenho insatisfatório ou absenteístas, por exemplo, substituindo-os por outros mais determinados para o trabalho pode resultar numa conta positiva. Silva (2001) comenta que, junto com novos funcionários, a empresa recebe novas ideias, novos conhecimentos, formas diferentes de trabalhar e inovação. Outra implicação positiva do turnover está na redução de quadro e consequente redução de despesas com pessoal. Quando um cargo está vago e se observa que a atividade atribuída a ele continua sendo exercida, sem sobrecarregar a equipe e sem perda de qualidade, é o momento de avaliar a necessidade de mão de obra naquele posto. Muitas vezes a possibilidade de ajuste no quadro só é percebida com a ausência do profissional em seu posto. O autor também detecta o turnover como positivo, quando o desligamento se faz necessário (sendo uma vantajosa opção para a empresa), isto é, quando o colaborador tem a 
intenção de se desligar, mas ainda não conseguiu realocação no mercado, forçando o processo por meio de faltas, baixa produtividade, sabotagem e ou conflitos.

Todavia, é importante destacar que o maior dano ocasionado pelo turnover não é o financeiro; é o custo operacional. O impacto na produção é imediato. Além do acúmulo de trabalho ocasionado durante a seleção e treinamento do substituto, não se pode esperar do novo contratado uma boa produtividade ao assumir a função. Ele precisará de tempo para desenvolver habilidades e dominar com agilidade suas tarefas. Enquanto isso, a operação pode sofrer alterações e perdas. Além disso, é difícil conservar a história da empresa se as pessoas sempre passam por ela por curto período de tempo. Sem falar no desafio de difundir a cultura e valores com novos colaboradores. Destarte, a retenção de pessoas tornou-se um indicador para as organizações e uma meta para o setor de recursos humanos.

A retenção de pessoas é uma prática realizada pela empresa para a fidelização de seus colaboradores, por meio de atrativos de crescimento, incentivos, além do desenvolvimento profissional e pessoal. Para definir práticas de retenção, a GRH deve estudar os anseios dos colaboradores e descobrir o que move sua intenção de ficar. A retenção de pessoas resulta, portanto, na diminuição de todas as consequências geradas pela efetivação do turnover: reduz custos financeiros, custos operacionais, custos com recrutamento e capacitação; evita perda de produtividade e impacto sobre o desempenho de demais colaboradores da equipe; reduz o tempo investido no desenvolvimento de um novo profissional, entre outros (Toledo, 2009).

As práticas de recursos humanos são necessárias ao processo de retenção, mas são as lideranças que exercerão forte influência nesse processo. O investimento feito no profissional gera resultados satisfatórios para a empresa, que compreenderá em seu quadro pessoas de elevado potencial. Sentindo-se valorizados, esses funcionários adicionarão comprometimento, motivação e esforço ao seu trabalho; se sentirão parte do negócio e, consequentemente, se tornarão mais comprometidos. A gestão de talentos requer planejamento, comprometimento, integridade e conhecimento. Por isso, os profissionais de GRH, que têm o treinamento e a experiência técnica, devem ser incluídos nesse processo de planejamento e, sendo necessário, de reestruturação. Tal envolvimento irá garantir que a 
organização otimize a retenção dos seus talentos (Kavoo-Linge \& Kamoche, 2015).

A premiação e o reconhecimento são, em geral, utilizados pelos gestores como uma forma de motivação dos empregados, visando atingir seus objetivos de retenção dos talentos. Conforme os autores supracitados, vários estudos, inclusive, estabelecem que existe uma ligação entre o desempenho do profissional e o retorno (premiação ou reconhecimento) que é recebido. No processo de retenção de empregados, as organizações precisam considerar fatores importantes como: os comportamentos que serão motivadores da retenção (o tipo de desempenho valorizado); os resultados pretendidos (o tipo de talento a ser retido); e as condições a serem oferecidas para que a retenção seja sustentada (forma de mitigação do risco de desligamento motivado pelo empregado).

\section{$3 \quad$ Metodologia}

Para alcançar o objetivo do estudo, foi realizada pesquisa do tipo descritiva, utilizando abordagem qualitativa e quantitativa, tendo como método o estudo de caso realizado por meio da pesquisa de campo e documental.

A pesquisa foi realizada na Organização Verdemar, que emprega cerca de 3.000 funcionários. No tocante aos aspectos qualitativos, a unidade de observação foi composta pelos líderes de determinados setores (mais representativos) da organização e por três especialistas em recursos humanos. Já em relação à pesquisa quantitativa, o dimensionamento da quantidade de elementos a serem pesquisados deu-se por meio de fórmulas da amostragem probabilísticas, sendo adotado o critério de $6 \%$ de erro e de 95\% de confiança, chegando-se a um número mínimo da amostra de 247 funcionários. A pesquisa foi realizada em seis unidades da empresa em análise. A aplicação dos questionários ocorreu no período compreendido entre os meses de setembro e outubro de 2015.

Este trabalho utilizou fontes de dados primárias e secundárias. Como fonte de dados primários, destacam-se o questionário aplicado aos funcionários e as entrevistas realizadas com os especialistas de $\mathrm{RH}$ e com os líderes dos setores. As fontes de dados secundários utilizadas foram as 
compilações das entrevistas de desligamento apuradas mensalmente, os dados relativos ao índice de turnover e o tempo médio de permanência dos funcionários.

Em função da concisão necessária ao relato técnico, o item sobre os resultados obtidos e sua análise tem como meta mostrar os principais aspectos da pesquisa completa que serviu de base para este texto. No tocante à coleta e à análise de dados, o tipo de intervenção adotado foi de um parecer técnico, composto pelas etapas:

- Coleta de dados: realizada, inicialmente, por meio da pesquisa documental com a solicitação dos dados à empresa e a análise dos seguintes dados: turnover geral da empresa, turnover dos setores investigados, absenteísmo, tempo médio de permanência dos funcionários na empresa e os relatórios dos motivos de desligamentos. Todos os dados são do período de 2013, 2014 e 2015. Posteriormente, a pesquisa de campo teve início com entrevistas a três especialistas em Recursos Humanos (de outras empresas) visando validar conceitos estudados no referencial teórico e ampliar a percepção sobre as práticas de $\mathrm{RH}$ voltadas para a gestão do turnover. Como resultado, foi desenvolvido um roteiro semiestruturado aplicado aos líderes dos setores pesquisados. A aplicação dos questionários aos funcionários e as entrevistas com os líderes foram realizadas por meio do contato pessoal. Já as entrevistas com os especialistas em RH foram feitas por e-mail. Baseados nas análises anteriores, pesquisa documental e nas entrevistas, foi realizada a última etapa de coleta de dados que consistiu de um survey aplicado em uma amostra de 253 funcionários, visando identificar e mensurar as percepções dos respondentes a fatores relacionados ao turnover, assim como às políticas de RH utilizadas pela empresa para controlar esse indicador.

- Análise de dados: para a etapa qualitativa da pesquisa, foi utilizada a técnica do Discurso do Sujeito Coletivo (DSC), que é uma proposta de organização e tabulação de dados qualitativos de natureza verbal, obtidos de depoimentos, resultando na apresentação de resultados sob a forma de um ou vários discursos-síntese escritos na primeira pessoa do singular, expediente que visa expressar o pensamento de uma coletividade, como se essa coletividade fosse o emissor de um discurso (Lefèvre, Lefèvre \& Teixeira, 2000). Para a etapa quantitativa da pesquisa, foram realizados 
os seguintes procedimentos: a limpeza de dados, a análise de confiabilidade do questionário aplicado por meio do coeficiente Alfa de Cronbach e a estatística descritiva dos respondentes e respostas coletadas.

\section{$4 \quad$ Resultados Obtidos e Análise}

Os resultados obtidos e sua respectiva análise são apresentados em três seções: a pesquisa nos documentos da organização, a pesquisa realizada junto aos funcionários e a pesquisa feita com especialistas em Recursos Humanos (de outras organizações) e líderes da organização pesquisada.

\subsection{Pesquisa Documental}

A Tabela 1 apresenta os resultados compilados do turnover geral da empresa, da taxa de absenteísmo e dos motivos de desligamentos.

\section{Tabela 1}

Turnover, absenteísmo e motivos de desligamentos

Ano Turnover Absenteísmo

3 motivos de desligamento mais citados

Trabalho no final de semana/horário de trabalho

2013

$5,30 \%$

$5,20 \%$

2014

$20154,30 \%$

$5,42 \%$

Oportunidade na área de formação

Baixa produtividade

Trabalho no final de semana/horário de trabalho

5,35\% Excessos de faltas e atestados

Distância de casa/Trabalho

Trabalho no final de semana/horário de trabalho

2015

$4,32 \%$

Excessos de faltas e atestados

Redução de quadro

Fonte: Dados da pesquisa (2016).

- Turnover geral da empresa: apurado mensalmente pelo setor de RH e os dados são referentes a todos os funcionários ativos, admitidos e demitidos em todas as unidades da empresa. Observa-se uma redução de 1 ponto percentual entre os anos de 2013 e 2015, realidade justificada, em grande parte, pela crise política e econômica que o país enfrentou no ano de 2015 (demandando um ajuste de quadro).

- Absenteísmo: a redução dos índices de absenteísmo observada reflete o aumento do comprometimento e a preocupação dos funcionários em serem 
dispensados da empresa (justamente em função da crise política e econômica vivenciada).

- Motivos de desligamento: obtidos por meio das entrevistas realizadas pelo setor de $\mathrm{RH}$, com todos os funcionários desligados da empresa (levantamento das razões que levam os funcionários a não desejar continuar na empresa, nos casos de pedidos de dispensa) e, para os casos de desligamentos demandados pela organização, informações repassadas pelas respectivas lideranças (motivos que geraram a dispensa dos funcionários).

\subsection{Pesquisa com Funcionários}

Utilizou-se o Alfa de Cronbach, que é a medida mais simples de consistência interna, para a avaliação da confiabilidade. A confiabilidade de uma medida refere-se à capacidade desta em ser consistente, ou seja, mostra até que ponto uma escala produz resultados consistentes se as medidas forem tomadas repetidamente. O Alfa de Cronbach toma valores entre zero e um. Hair, Babin, Money e Samouel (2005) propõem que o limite inferior para o Alfa de Cronbach geralmente aceito é 0,70, apesar de poder diminuir para 0,60 em pesquisa exploratória.

A avaliação da confiabilidade foi realizada conforme a classificação dos temas componentes da pesquisa, que são os escores: antecedentes, mediadores, consequências do turnover e as práticas de $\mathrm{RH}$ adotadas na organização, conforme Tabela 2.

\section{Tabela 2}

Valores de Alfa de Cronbach por escores

\begin{tabular}{lcc}
\multicolumn{1}{c}{ Escores } & Alfa de Cronbach & N de itens \\
Antecedentes & 0,871 & 10 \\
Mediadores & 0,821 & 18 \\
Consequências & 0,786 & 18 \\
Recursos Humanos & 0,911 & 21 \\
\hline
\end{tabular}

Fonte: Dados da pesquisa (2016).

Considerando cada questionário como um escore, observou-se valor de Alfa de Cronbach superior a 0,7 em todos os escores, indicando a boa consistência da escala. 
A Tabela 3 apresenta as questões do survey, estruturado por meio da escala Likert, variando de um (discordo totalmente) a cinco (concordo totalmente). Para cada questão apresentada, é possível visualizar o percentual obtido em relação ao máximo de total concordância.

\section{Tabela 3}

\section{Análise descritiva das escalas do questionário}

O salário é a principal razão da minha permanência nesta empresa.

O trabalho em equipe é a principal razão da minha permanência nesta empresa.

O ambiente de trabalho é a principal razão da minha permanência nesta empresa.

A atuação do meu líder é a principal razão da minha permanência nesta empresa.

56

O reconhecimento do meu trabalho é a principal razão da minha permanência nesta empresa.

Os benefícios (alimentação, plano de saúde, convênios, etc.) são as principais razões da minha permanência na empresa.

A possibilidade de promoção é a principal razão da minha permanência nesta empresa.

A comunicação aberta é a principal razão da minha permanência nesta empresa.

O aprendizado contínuo é a principal razão da minha permanência nesta empresa.

O respeito aos funcionários é a principal razão da minha permanência nesta empresa.

Os funcionários são escutados a respeito das suas dificuldades e queixas.

Nesta empresa os funcionários são tratados com respeito.

Os colegas de trabalho ajudam uns aos outros.

Os funcionários têm possibilidade serem promovidos nesta empresa, por meio de recrutamento interno.

Nesta organização existe bom clima para o trabalho.

Na empresa, os líderes incentivam o trabalho em equipe.

O salário dos funcionários é compatível com o mercado e empresas do mesmo segmento.

Os funcionários sentem orgulho de trabalhar nesta empresa.

Nesta organização, um empregado pode ser demitido sem receber explicações convincentes.

O empregado pode acreditar nas informações que esta organização divulga.

A demissão de empregados segue procedimento conhecido por todos.

Esta organização é reconhecida no segmento do varejo.

O trabalho do empregado é reconhecido, por esta organização, por meio do salário.

Esta organização é melhor que as outras empresas em que trabalhei.

Os líderes desta empresa são bons profissionais.

As políticas de recursos humanos são um diferencial positivo desta organização. 
Eu perderia a liberdade que tenho de realizar meu trabalho, já conquistada dentro desta empresa.

Eu estaria desperdiçando todo o tempo que já me dediquei a esta empresa.

Eu estaria prejudicando minha vida profissional.

Eu demoraria a conseguir ser tão respeitado em outra empresa como sou hoje dentro desta empresa.

Eu deixaria de receber vários benefícios que esta empresa oferece (vale-transporte, convênio médico, alimentação, etc.).

Eu teria mais coisas a perder do que a ganhar com o desligamento.

Eu perderia o prestígio que tenho hoje por ser empregado desta empresa.

Eu levaria muito tempo para me acostumar a um novo trabalho.

Eu estaria jogando fora todo o esforço que fiz para aprender as tarefas do meu cargo atual.

Eu teria dificuldade de encontrar outro líder que me orientasse e desenvolvesse com o meu líder atual.

Eu ficaria mais feliz, porque não estou satisfeito com o salário.

Eu não procuraria outro emprego; no momento iria me dedicar somente à família.

Eu só aceitaria outro emprego se não trabalhasse no final de semana.

Eu mudaria de ramo de atividade, não desejo mais trabalhar no segmento supermercadista.

Fonte: Dados da pesquisa (2016).

Quanto à análise descritiva das escalas do questionário:

- ANTECEDENTES: questões que levam os funcionários a permanecerem na empresa. Fatores mais significativos: aprendizado contínuo, reconhecimento do trabalho e possibilidade de promoção. Fatores menos relevantes: benefícios, atuação do líder e trabalho em equipe.

- MEDIADORES: questões sobre o que leva os funcionários a terem respeito pela empresa. Para as questões de lógica inversa, os valores foram invertidos. Fatores mais significativos: reconhecimento da organização no varejo e treinamentos para o exercício das atividades. Fatores menos relevantes: reconhecimento do trabalho pela organização, atenção à opinião dos funcionários e auxílio dos colegas de trabalho.

- CONSEQUÊNCIAS: questões referentes às perdas e dificuldades que o funcionário teria caso pedisse demissão ou fosse desligado da empresa. Para as questões de lógica inversa, os valores foram invertidos. Consequências negativas: o funcionário perderia mais do que ganharia com a saída. Consequências positivas: pela insatisfação com o salário a saída seria boa, por ter outro trabalho em vista a adaptação seria mais fácil de ser vivenciada.

Quanto à caracterização dos respondentes:

- GÊNERO / ESTADO CIVIL / IDADE: os funcionários amostrados são, a maioria, do sexo feminino $(60,5 \%)$, solteiros $(73,9 \%)$, com idade média de 27,5 anos.

- FORMAÇÃO: apenas $11(4,4 \%)$ dos 253 funcionários entrevistados possuem ensino superior incompleto, completo ou pós-graduação. Aproximadamente um terço possui ensino fundamental incompleto ou 
completo, $23,3 \%$ têm ensino médio incompleto e $60,1 \%$ possuem o ensino médio completo.

- UNIDADES: os 253 trabalhadores pesquisados trabalham distribuídos em seis unidades da organização, sendo 39,1\% na unidade Sion, 17,8\% na unidade Jardim Canadá, $15,8 \%$ na unidade Buritis, $10,7 \%$ na unidade São Pedro, 9,1\% na unidade Raja e 7,5\% na unidade Diamond Mall.

- SETORES / CARGOS: aproximadamente metade dos funcionários entrevistados $(47,5 \%)$ atua no setor de frente de loja (operador de caixa, repositores, embaladores, atendentes, promotores de venda) e os demais estão distribuídos nos setores de mercearia (18,6\%), pizzaria $(13,8 \%)$, fatiados $(8,7 \%)$, perecíveis $(6,7 \%)$ e segurança $(4,7 \%)$. O cargo de operador de caixa é ocupado por aproximadamente um terço $(32,0 \%)$ dos entrevistados, seguido dos repositores (24,5\%), embaladores $(15,8 \%)$, atendentes $(7,9 \%)$ e promotores de vendas $(5,5 \%)$.

- TURNOS: os funcionários estão distribuídos nos turnos da manhã $(49,6 \%)$ e tarde $(48,8 \%)$. Apenas $1,6 \%$ trabalha no turno intermediário.

- TEMPO DE CASA: pouco mais de metade dos funcionários entrevistados trabalha na organização há menos de um ano, 31,2\% trabalham entre um e três anos, $11,1 \%$ trabalham entre três e cinco anos e 6,7\% trabalham há mais de cinco anos. O mínimo de tempo de trabalho na empresa verificado foi de seis dias (um funcionário), seguido de uma semana (três funcionários). No total, 12 funcionários trabalham um mês ou menos na organização. Já o tempo máximo foi de 10 anos (dois funcionários).

\subsection{Pesquisa com Especialistas e Líderes da Organização}

$\mathrm{Na}$ pesquisa completa, são apresentados os roteiros da entrevista semiestruturada, dividida entre a caracterização dos respondentes e perguntas sobre a gestão do turnover, seguida da análise por meio do DSC. Neste relato, são apresentados os resultados compilados dos principais pontos abordados, conforme Tabela 4. 


\section{Tabela 4}

\section{Principais análises do Discurso do Sujeito Coletivo dos especialistas e} dos líderes da organização

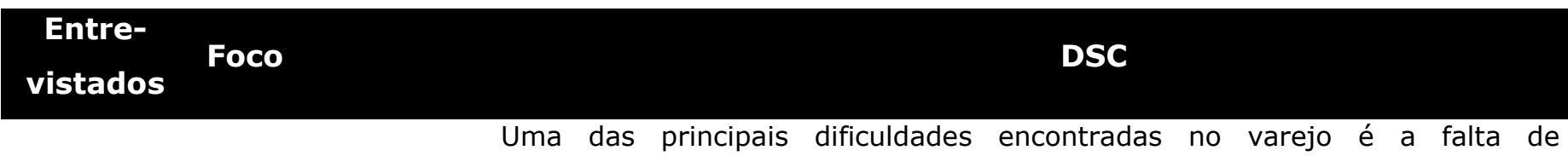

Percepção sobre o comprometimento por parte dos funcionários, a remuneração menor e a turnover frequente contratação sem experiência. É um setor com alto turnover, levando à perda de talentos e ao desperdício com treinamento e qualificação.

Falta de treinamento e acompanhamento, falta de estrutura, falta de plano de

Fatores

influenciam

diretamente

turnover

carreira. No setor: incompetência de líderes, desconhecimento da tarefa como um todo, falta de feedback, atividades repetitivas e com grande esforço físico.

no Em relação às pessoas: falta de oportunidade de desenvolvimento, crescimento e remuneração baixa, falta de confiança e desmotivação e a política de benefícios.

Funcionários descomprometidos, salários baixos, falta de paciência da liderança Principais motivos em formar os profissionais, horário de trabalho, mercado instável, melhores de rotatividade propostas salariais, não adaptação ao tipo de atividades, comportamento inadequado e falta de capacidade técnica.

Melhorar critérios de seleção, treinar os líderes e os demais profissionais, Medidas tomadas implantar políticas de remuneração e benefícios, melhorar o ambiente do $\mathrm{p} /$ diminuir $\mathrm{o}$ trabalho, realizar pesquisas de desligamentos, pesquisas de clima fazendo turnover gestão dos pontos críticos, avaliação de desempenho e de carreira, melhorias na comunicação, criação de uma cultura com base em valores organizacionais. O índice no varejo é alto, apesar de ser menor no Verdemar. Influências: contratação de funcionários de primeiro emprego e de muitas pessoas que não

Avaliação do turnover no varejo e investimentos no funcionário. No Verdemar, há ensinamentos, cursos, treinamentos e oportunidades de crescimento. Outros fatores: distância da loja para trabalhar no fechamento e os horários dos ônibus.

Sim. É um problema para todo comércio varejista, mas o Verdemar trabalha com um diferencial dando maior satisfação e valorização ao funcionário, buscando estabilizar o turnover. Considero um problema sério e urgente, principalmente pela perda de capital intelectual, perda de conexão com o cliente e impacto no rendimento da equipe.

Não. O Verdemar trabalha bem a retenção de funcionários. Quando ocorre desligamento, já tentamos todas as possibilidades de retenção. Além disso, tem outros fatores que são problemas piores dentro do Verdemar. Entendo que em todas as empresas existe insatisfação. 
Continuação

No Verdemar: prática de melhor salário do mercado, oportunidade de

Medidas tomadas

p/ diminuir 0

turnover

Efeitos positivos e negativos

turnover crescimento, diálogo, acompanhamento e treinamento, admissão de funcionários para as unidades mais perto das suas casas, transparência e objetividade, acompanhamentos diários, reuniões e intervenções e benefícios atrativos. A empresa tem o RH muito comprometido com seus colaboradores e tenta o diálogo antes de decisões finais de desligamento.

Reflexos negativos: ter sempre uma equipe "nova" sem conhecimentos necessários para atender à empresa, dificuldades na formação da equipe, ausência de pessoas de confiança e com conhecimento necessário para exercer sua função. Custo financeiro e investimento em tempo para treinamento e formação profissional. Formamos profissionais e depois perdemos para o mercado. Impacto na operação. Desfalque na equipe, desestruturação da equipe.

Reflexos positivos: quando pessoas que a empresa deveria mandar embora pedem conta, gerando custo menor. Não perde-se tempo com quem não quer trabalhar. Permite renovação do quadro; contratar pessoas mais motivadas e comprometidas com o trabalho.

Fonte: Dados da pesquisa (2016).

Considerando o objetivo de identificar os motivos de desligamentos da organização investigada, observa-se que o motivo "folga nos finais de semanas/horário de trabalho" é o de mais representatividade. A ação de colher os motivos de desligamentos, seguida da compilação e discussão analítica, visando traçar planos de ações que minimizem os desligamentos indesejáveis e as falhas na gestão das lideranças da empresa, condiz com as afirmações localizadas no referencial teórico desta pesquisa, em que Ulrich (1998) informa que as práticas de RH devem ajudar a realizar objetivos empresariais.

Considerando o objetivo específico de identificar as principais formas de gerenciamento do turnover, as medidas tomadas pelo entrevistados, visando diminuir o turnover, são: melhorar os critérios de seleção, treinar os líderes e os demais profissionais, implantar políticas de remuneração e benefícios, melhorar o ambiente do trabalho, realizar pesquisas de desligamentos, pesquisas de clima, melhorias na comunicação e a criação de uma cultura com base em valores organizacionais. Vale destacar que, de acordo com o referencial teórico, no processo de retenção, para Kavoo-Linge 
\& Kamoche, (2015), o papel da liderança é significativo. Porém, os líderes salientam que a gestão do RH pode melhorar nos seguintes pontos: na gestão dos benefícios, como plano de saúde e cestas básicas, a redução de jornada nos finais de semana, com o aumento da agilidade e assertividade do processo de seleção e contratação de funcionários, com mais atenção com as indicações das lideranças para as contratações de funcionários, realizando treinamentos para reduzir o turnover e oferecendo mais oportunidades de crescimento.

\section{Considerações Finais}

Em geral, as práticas do RH da Verdemar são percebidas pelos funcionários, como mostrado na pesquisa quantitativa, como diferencial da empresa. Neste sentido, o investimento na gestão de recursos humanos tem gerado vantagem competitiva na retenção de funcionários. Projetos de inserção de mão de obra de primeiro emprego, de terceira idade e de portadores de deficiência também foram bem avaliados no questionário da pesquisa quantitativa com mais de $80 \%$ de concordância. Outra prática que agrada na organização é o funcionário sentir-se ouvido pelos profissionais do $\mathrm{RH}$ quando precisa resolver suas insatisfações. Esse item foi bem avaliado, abrangendo concordância de $73 \%$ dos funcionários pesquisados.

Considerando os resultados da pesquisa qualitativa, para as lideranças dos setores e dos especialistas em $\mathrm{RH}$ os custos financeiros e a queda do desempenho são os impactos mais preocupantes do turnover. Isso confere com os estudos de Silva (2001) e Mobley (1992), mencionados no referencial teórico desta pesquisa. Além do custo e da queda no desempenho, os líderes evidenciam outras especificidades do segmento do comércio supermercadista que favorecem o turnover: o trabalho nos finais de semana, baixos salários e pouco investimento na formação dos profissionais. Então, as empresas do comércio varejista que pretendem reduzir e estabilizar seu indicador de turnover precisam desenvolver ações que favoreçam a adequação da jornada, o aumento salarial e a formação profissional.

Conclui-se que o investimento nas políticas e práticas de recursos humanos gera resultados tangíveis para o negócio. Com o controle do turnover, a economia financeira é perceptível nos índices de custo de pessoas 
sobre o faturamento, que é a consolidação de todos os custos com pessoas, desde o recrutamento até o final do seu vínculo com a organização. Há ainda aspectos de mais difícil mensuração, como retenção do conhecimento das atividades e da cultura organizacional, assim como a queda da produtividade e do atendimento em concordância com o que foi verificado no referencial teórico nos estudos de Silva (2001) e Mobley (1992).

O presente trabalho possibilitará que a empresa analise e ajuste suas práticas que são passíveis de melhorias, tendo em vista as percepções de seus funcionários, lideranças e de especialista de RH. As investigações e os apontamentos não se limitam à organização estudada, tendo em vista as similares deficiências do ramo varejista, em especial dos supermercadistas. Conclui-se, ainda, que por meio das pesquisas acadêmicas os pesquisadores podem contribuir para a melhoria das condições de trabalho e da satisfação dos empregados e dos empregadores, ressaltando a necessidade da continuidade e ampliação das pesquisas de campo nas organizações. 


\section{Referências}

Departamento Intersindical de Estatística e Estudos Socioeconômicos. (2015). Os números da rotatividade no Brasil: um olhar sobre os dados da Rais 2002-2013. Recuperado em 20 dezembro, 2015, de http://tinyurl.com/DIEESE-ROTATIVIDADE

Dutra, J. S. (2011). Gestão de pessoas: modelo, processo, tendências e perspectivas. São Paulo, Atlas.

Hair Jr, J. F., Babin, B., Money, A. H., \& Samouel, P. (2005). Fundamentos de métodos de pesquisa em administração. Porto Alegre, Bookman.

Kavoo-Linge, T., \& Kamoche, M. W. (2015). Talent Management Approaches for Restructuring: a case of non-governmental organizations in Kenya. International Journal of Business and Social Science, 6(5), 47-53.

Lacombe, B. M. B., \& Albuquerque, L. G. (2008). Avaliação e mensuração de resultados em gestão de pessoas: um estudo com as maiores empresas instaladas no Brasil. Revista de Administração, 43(1), 5-16.

Lefèvre, F., Lefèvre, A. M. C., \& Teixeira, J. J. V. (2000). O discurso do sujeito coletivo: uma nova abordagem metodológica em pesquisa qualitativa. Caxias do Sul: EDUCS.

Marras, J. P. (2000). Administração de recursos humanos: do operacional ao estratégico. (3. ed.). São Paulo, Futura.

Menicucci, C. M. B. de F., \& Jeunon, E. E. (2008). O turnover na hotelaria econômica. ANPTUR - Seminário da Associação Brasileira de Pesquisa e Pós-graduação em Turismo em Belo Horizonte.

Mobley, W. H. (1992). Turnover: causas, consequências e controle. Porto Alegre: Ortiz.

Morrell K., Loan-Clarke, J., \& Wilkinson, A. (2001). Unweaving leaving: the use of models in the management of employee turnover. International Journal of Management Reviews, 3(3), 219-244.

Silva, G. L. R. (2001). Controle do turnover: como prevenir e demitir com responsabilidade. Rio de Janeiro: Qualitymark .

Silva, M. F. (2002). Comportamento organizacional: a rotatividade em foco. Revista de Psicologia - Fortaleza, 20(2), 59-70. 
Toledo, F. (2009). Administração de pessoal: desenvolvimento de recursos humanos. São Paulo: Atlas.

Ulrich, D. (1998). Os campeões de recursos humanos: inovando para obter melhores resultados. São Paulo, Futura. 